\title{
Advancing Green Manufacturing for Ecological Civilization: Research on Green Manufacturing Strategies in China
}

\author{
The Research Group for Research on Green Manufacturing Strategy
}

\begin{abstract}
China is experiencing an important historical stage as it transforms from a large manufacturing country into a global manufacturing power. With the green development concept, China must explore the strategic issues on advancing the coordinated development between the manufacturing industry and ecological environment, for the harmonious coexistence between industrial civilization and ecological civilization. Green manufacturing is a critical focus in the construction of manufacturing power and in the transformation of production modes. Moreover, green manufacturing is an important part of green development. Green manufacturing includes low carbon development and circular development. This paper elaborates the scientific implications, targets, and evaluation system of green manufacturing, based on clarifying the relationship between green manufacturing and ecological civilization. The authors subsequently propose the strategic direction and major projects for green manufacturing, based on the achievements and difficulties of the current development. Policy implications are provided from the aspects of top-level design, team construction, innovation system, service platform, system and mechanism, and international cooperation.
\end{abstract}

Keywords: ecological civilization; green manufacturing; engineering science and technology; strategic countermeasures

China's high-growth industrial economy has made remarkable achievements since the policy of reform and opening Up in 1978. However, the extensive growth mode of high consumption, high emission, and low efficiency has simultaneously brought a series of serious problems regarding the resources, environment, ecology, and social livelihood [1]. The effort to tackle the contradiction between economic growth and ecoenvironmental protection has become a realistic problem for China and requires urgent attention. As such, China desperately needs to achieve efficient, clean, low carbon, recycling, and sustainable development, to promote the harmonious coexistence between industrial civilization and ecological civilization. To solve the development problems and construct a beautiful country, the 18th National Congress of the Communist Party of China (CPC) has proposed to "vigorously promote the construction of ecological civilization," and incorporate it into the overall layout of the cause on socialism with Chinese characteristics.
The essence is to accelerate the transformation of the economic development mode and improve the quality and efficiency of development, to achieve green development. Subsequently, the fifth plenary session of the 18th Central Committee of the CPC further proposed the five development concepts of "innovation, harmony, green, open, and sharing." This time, the goal, principles, primary tasks, path realization, and safeguard measures of green development have been clarified. These significant decisions have indicated the direction for solving the problems mentioned above regarding unsustainable development [2].

\section{Ecological civilization construction and green manufacturing}

Ecological civilization is a new civilization form following primitive civilization, agricultural civilization, and industrial civilization [3]. The core of ecological civilization is "the harmony

Received date: April 25, 2017; Revised date: May 16, 2017 
between human and nature," which emphasizes the harmonious co-existence of human and nature and the sustainable development of human society $[1,2,4]$. The construction of ecological civilization has shown to not only protect the ecological environment, but also to change the traditional mode of development, and to establish the endogenous mechanism toward the balance between human and nature. We should protect the ecological environment, and meanwhile, construct a new human society by learning and imitating the laws of nature to realize the sustainable development of the human society.

Green-, low-carbon-, and circular-development are the primary principles and directions for the construction of ecological civilization. Among them, green development is the most important and fundamental, while low carbon and circular development are the focus of and path to green development. The broad sense of green development covers all the contents of low carbon and circular development. It is based on the harmonious co-existence of human and nature, to realize a sustainable development of human society, by changing the method of production and consumption.

The real economy is the source of wealth, and the manufacturing industry is the foundation of China. National rejuvenation depends on the construction of a manufacturing power. Green manufacturing is a critical focus in the construction of a manufacturing power and a significant part of China's green development [2]. Made in China 2025 clarifies the strategic significance of fully promoting green manufacturing and implementing green manufacturing engineering, which are listed in the nine major strategic tasks and five major projects. First, we will focus on the upgrading of the manufacturing sector to achieve cleanliness of production processes, low carbonization of energy utilization, high efficiency of water resources utilization, and ecologicalization of basic manufacturing processes. We will promote the circular mode of production and cultivate an additional manufacturing industry. Next, we will vigorously promote the research and development and industrialization of key technologies of green manufacturing, strive for breakthroughs in key energy-saving technical equipment, advance contract energy management and environmental protection services, and strengthen energy-saving and environmental protection industries. Subsequently, we will comprehensively promote the construction of the green manufacturing system. With enterprises as the primary body, we will accelerate the establishment of green standards, develop green products, set up green factories, build green parks, and consolidate green supervision and demonstrating guidance, by which we could promote the full realization of efficient, clean, low carbon, circular, and sustainable development of manufacturing industries, to achieve the harmonious symbiosis between industrial civilization and ecological civilization.

\section{Connotation, goal, and evaluation system of green manufacturing}

\subsection{Connotation of green manufacturing}

As an important part of green development, green manufacturing has the essence of environmental awareness, or environment consideration. Specifically, green manufacturing is a modern manufacturing mode considering people's needs, environmental impacts, resource efficiency, and enterprise benefits. It is a sustainable manufacturing mode with conscience, social responsibility, and impact.

\subsection{Goal of green manufacturing}

The goal of green manufacturing is to minimize the impact of products in a full life circle from design, manufacturing, use to scrapping, and to minimize natural hazards or minimize hazards, to maximize resource utilization and minimize energy consumption. Using flow manufacturing as an example, Fig. 1 shows the evolution trend of the function of steel manufacturing processes under the concept of green manufacturing.

As shown, the green manufacturing mode is a closedloop system, and is also a product manufacturing that uses the low-entropy mode. We must consider and solve a series of environmental problems in the manufacturing link from the raw material preparation, product manufacturing, use and maintenance, scrapping, to the recycling of secondary resources, from the overall theory and systems engineering perspective. The effect of environmental cost could be minimized by improving the quality and performance of products, extending the product life, and reducing the material and energy consumption from product manufacturing, while strengthening the eco-links between industries, and between industry and society (Fig. 2).

\subsection{Evaluation system for green manufacturing}

The goals above can be summarized as four key aspects: green product greenization, process ecologicalization, industry recycling, and industry intellectualization. Around these four aspects, the green degree, low carbon degree, circular degree, and smart degree can be used to quantificationally evaluate the green development of the manufacturing industry [5].

\subsubsection{The green degree}

The green degree (GD) is used to measure the degree of greenization of a product. It can be expressed by the ratio between the theoretical consumption of natural resources for a unit qualified product and the actual material consumption for the unit qualified product (Fig. 3). 


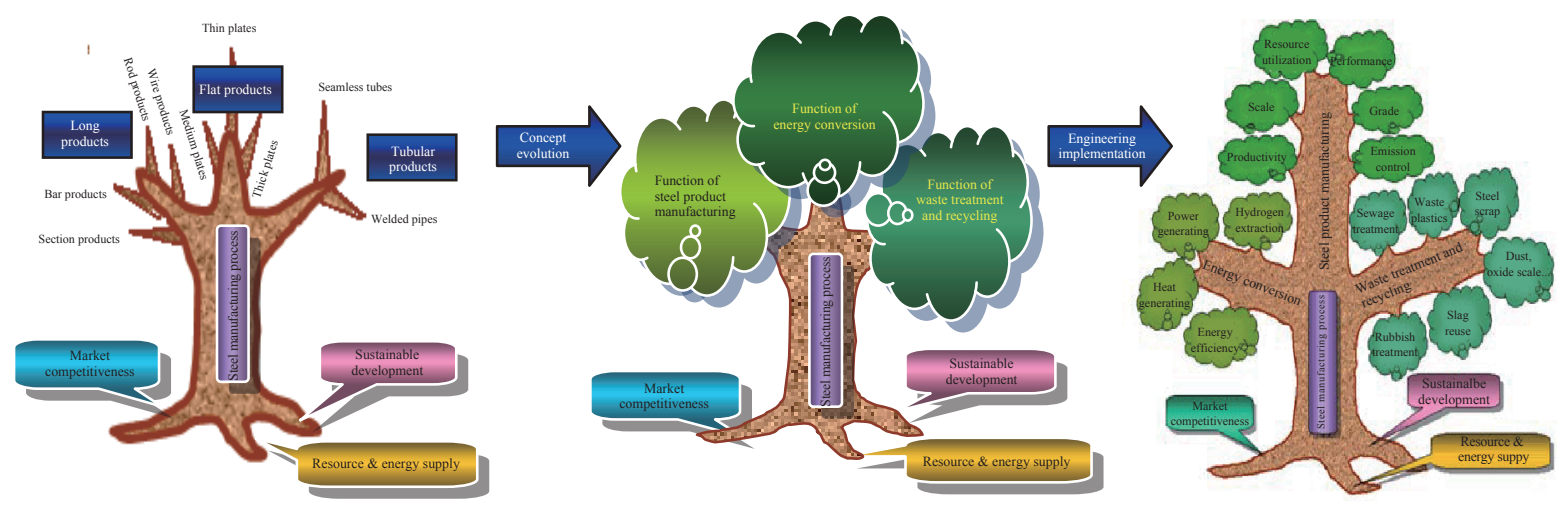

Fig. 1. Evolution trend of the functions of steel manufacturing processes [2].

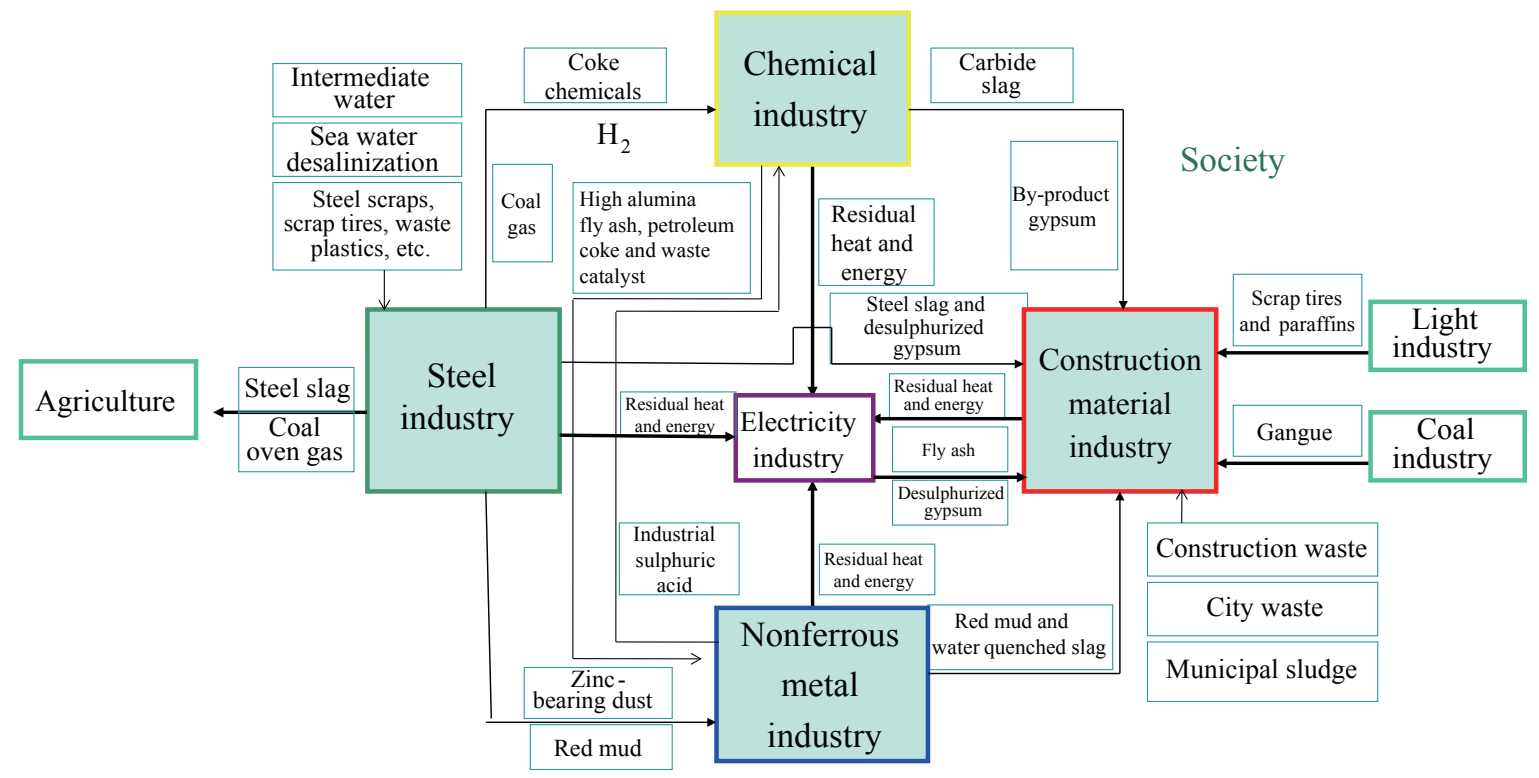

Fig. 2. Diagram of eco-link between flow industries, and between flow industry and society.

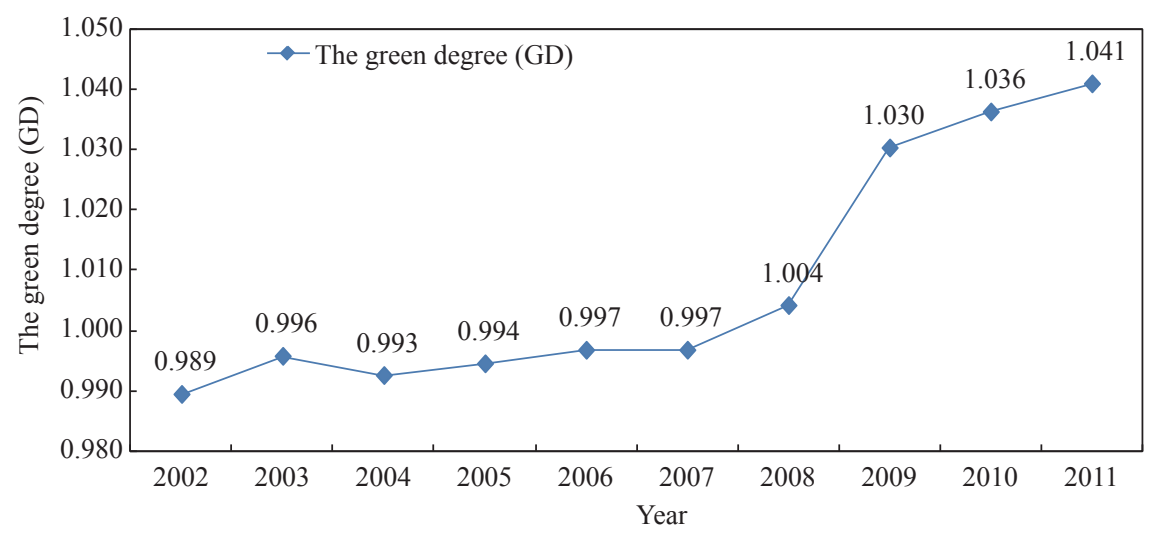

Fig. 3. Evolution trend of green degree from China's cement industry (2002-2011).

\subsubsection{The low carbon degree}

The low carbon degree (LCD) is used to measure the degree of low carbonization of the product manufacturing process. It can be expressed by the ratio between the international leading level of $\mathrm{CO}_{2}$ emissions for a unit qualified product and the actual total $\mathrm{CO}_{2}$ emissions for the unit qualified product. 


\subsubsection{The circular degree}

The circular degree $(\mathrm{CD})$ is used to measure the degree of recycling in the manufacturing industry. It can be expressed by the recycling of other industries' wastes during the production process (Fig. 4).

\subsubsection{The smart degree}

The smart degree (SD) is used to measure the intellectualization level of a producing enterprise. It can be expressed by the ratio between the output per capita of a certain producing enterprise and the output per capita of the most advanced business in the industry's counterparts (Fig. 5).

\section{Strategic choice of green manufacturing in China}

\subsection{Achievements of green manufacturing in China}

In recent years, China's manufacturing industry has been developing rapidly; the overall scale, independent innovation ability, and comprehensive strength have significantly improved. With the in-depth implementation of the green development concept, China has attained gratifying achievements in green manufacturing.

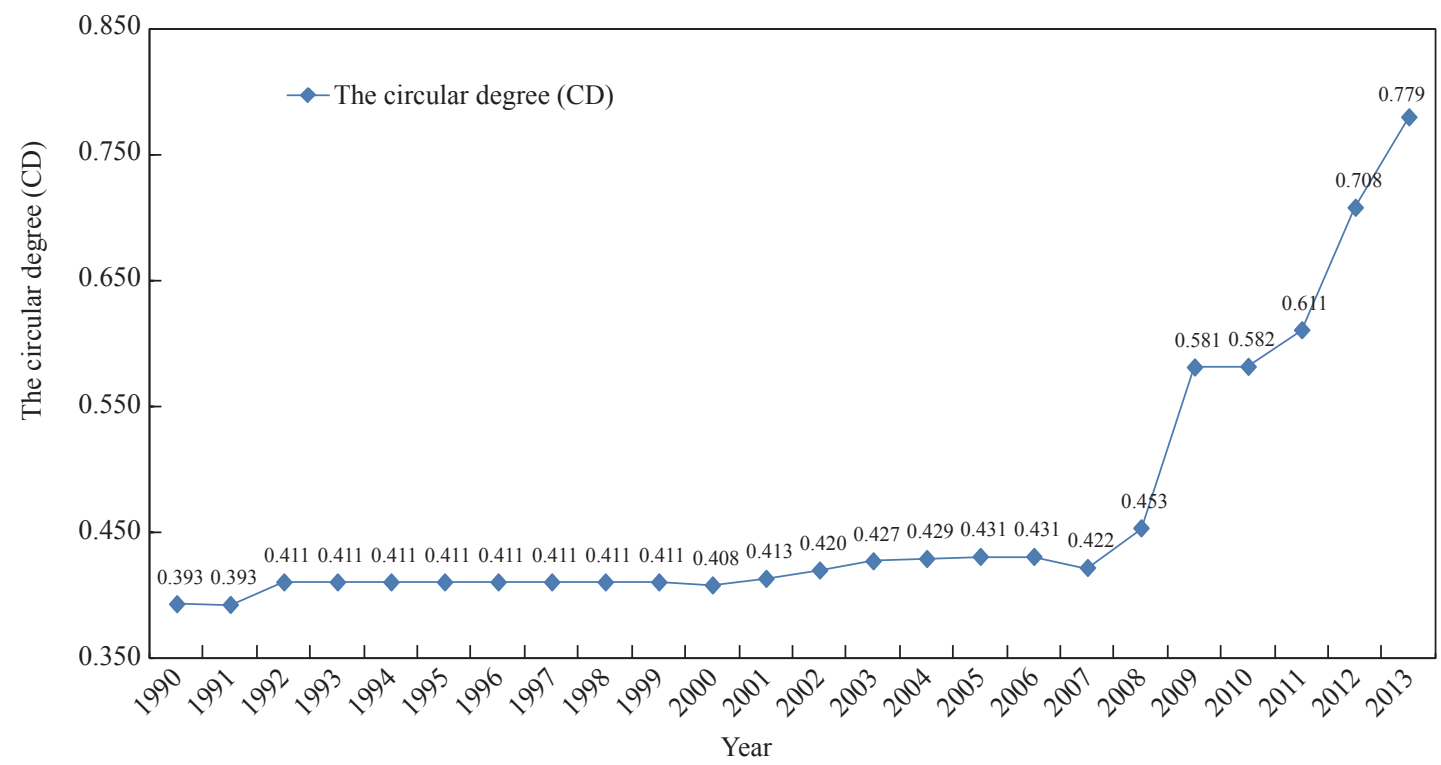

Fig. 4. Evolution trend of circular degree from China's cement industry (1990-2013).

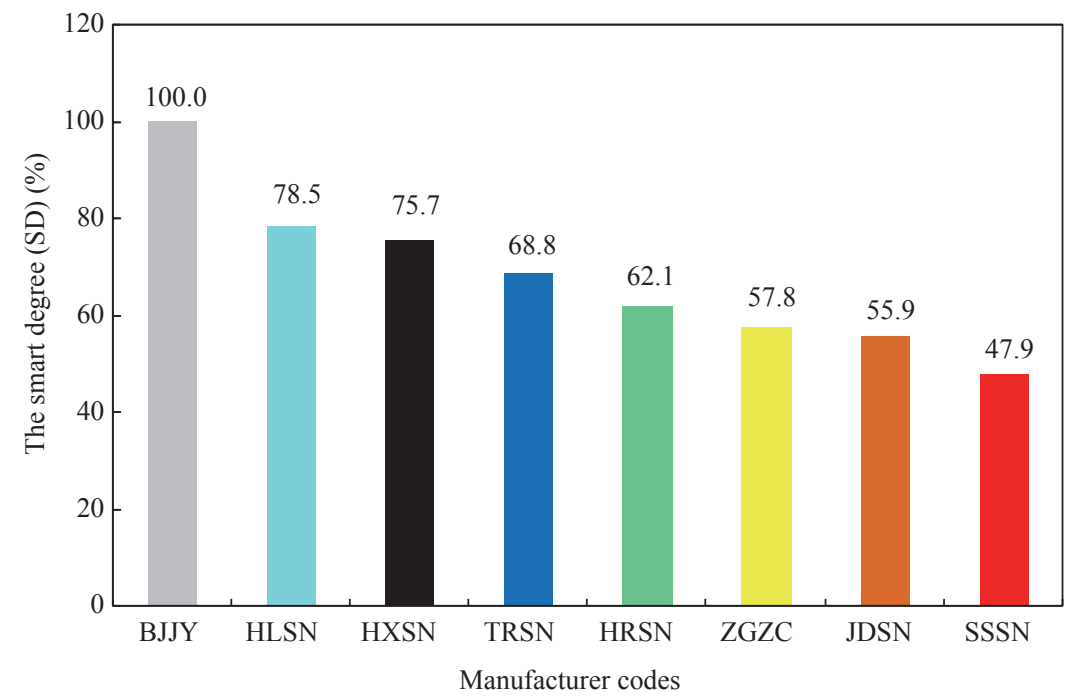

Fig. 5. Smart degree from the primary cement manufacturing enterprises in China (2015).

BJJY: BBMG Corporation; HLSN: Anhui Conch Cement Co., Ltd.; HXSN: Huaxin Cement Co., Ltd.; TRSN: Tianrui Cement Group Co., Ltd.; HRSN: China Resources Cement Holdings Limited; ZGZC: China National Building Materials Group Corporation; JDSN: Jidong Cement Co., Ltd.; SSSN: Shandong Shanshui Cement Group Limited. 
3.1.1 The adjustment of the industrial structure is progressing smoothly, and the quality and benefits are significantly improved

Intelligent manufacturing, high-speed rail transportation, marine engineering, and other high-end equipment manufacturing industries account for more than $10 \%$ of the output value of the equipment manufacturing industry. The new suspension pre-heaters or precalciners (NSP) cement production line account for $40 \%$ of the overseas market share, and the domestic brand smart phones correspond to more than $70 \%$ of the domestic market share. China fulfilled all the goals of the 12th Five-Year Plan to eliminate backward production capacity one year in advance. The internal structure of steel, construction materials, and other traditional manufacturing industries have been gradually optimized.

3.1.2 The level of comprehensive utilization of resources and energy is continuously improved, and the ability of green development is enhanced

During the period of the 12th Five-Year Plan, the national regulation of industrial units decreased more than $28 \%$ of the energy consumption, which contributed to over $80 \%$ of the whole society goal of energy saving. The proportion of energy consumption in the four high-load energy industries, such as the chemical industry, construction materials industry, steel industry, and nonferrous industry, was in a declining trend. Industrial energy saving, water saving, comprehensive utilization of resources, environmental protection, recycling of wastewater, and other key equipment and demonstration projects of equipment industrialization were actively promoted, and the energy-saving and environmental protection industry was developing rapidly. In 2015, China produced 3780 million tons of large industrial solid waste (excluding waste rocks), the comprehensive utilization capacity of which were 1740 million tons, with an increase of over 600 million tons; further, the comprehensive utilization rate was $50 \%$, with an increase of $10 \%$.

3.1.3 Green and clean production is further advanced, and the total amount of pollutant emissions continue to decline

In the fourth year of the 12th Five-Year Plan, industrial sulfur dioxide, nitrogen oxides, chemical oxygen demand, and ammonia nitrogen emissions decreased by $6.66 \%, 4.15 \%, 28.40 \%$ and $15.02 \%$, respectively. Further, the emission reduction targets were fulfilled one year ahead of schedule. The basic capacity of cleaner production was significantly enhanced, and the number of clean production advisory bodies increased significantly. Under the support of the central government's special funds for cleaner production, the cleaner production standard system was gradually improved, and a number of advanced cleaner production technologies and processes were widely popularized and promoted.

3.1.4 The concept of full life cycle has been spread, and a unified green product system has been gradually constructed

The promotion mechanism of green design for industrial products has been established. The pilot project of product ecological design has been performed, and the standard system of product ecological design has been gradually improved. The three ministries such as the Ministry of Industry and Information Technology of the People's Republic of China (PRC), the National Development and Reform Commission of the PRC, and the Ministry of Environmental Protection of the PRC, first released the Guidance on the Development of the Ecological design of Industrial Products which focused on formulating the evaluation criteria for the ecological design of typical products such as automobiles, electronic and electrical products, construction materials, and daily chemicals. We should vigorously promote green materials and products that are non-toxic and innocuous, or low toxic and low harm, and reduce the use of toxic and harmful substances such as mercury, six-valence chromium, lead, cadmium, arsenic, cyanide, and persistent organic pollutants.

3.1.5 Green manufacturing policy system has been advanced comprehensively

China successively released a series of special plans such as the Industrial Restructuring and Upgrading Plan (2011-2015), the 12th Five-Year Plan of Industrial Energy Saving, the 12th Five-Year Plan of Industrial Cleaner Production Implementation, the 12th Five-Year Plan of Comprehensive Utilization of Bulk Industrial Solid Waste, and the 12th Five-Year Plan of Environmental Protection Equipment during the period of the 12th Five-Year Plan. Additionally, China started the implementation of the first ten-year program of action for the manufacturing power strategy, i.e., Made in China 2025, in May 2015.

In the early years of the 13th Five-Year Plan, the Ministry of Industry and Information Technology of the PRC further released the Green Development Plan for Industry (2016-2020), the 2016 Special Action Implementation Plan for Green Manufacturing, the Guide to Standard System Construction of Green Manufacturing, etc.

\subsection{Problems and challenges of green manufacturing in China}

China's green manufacturing has achieved significant progresses and significant advancements. Nevertheless, it is weak despite being large-scaled, and some problems still persist such as the high input of manufacturing technology and equipment, high consumption, high pollution, low level, and low efficiency. The development of advanced and efficient green manufacturing technology and equipment is lagging behind, which directly affects the sustainable development of China's manufacturing industry.

In short, the following primary problems and challenges still persist in the green development of China's manufacturing industry.

(1) The ability of independent innovation is weak, and the overall technical level remains to be improved. The quality and 
technological level of the manufacturing personnel in China is not sufficient, and the product quality is still far from that of developed countries.

(2) The task of the supply-side reform is arduous. Currently, the overcapacity and oversupply in China's manufacturing industry is severe. Structural adjustments, energy-saving transformation and upgrading, and elimination of backward production capacity are slow. The backward products lead to the decline in the overall industry price and the serious loss of enterprises, causing the inability for upgrading and transformation.

(3) The total amounts of resource and energy consumption, and pollutant emissions are still large. China's manufacturing industry presents the characteristic of "two high and one low" on the whole. In other words, high consumption of resources, serious environmental pollutions, and the products being in the medium-to-low end of the value chain still remain.

(4) The level of intelligent manufacturing is low. The overall informatization level of China's manufacturing industry is low, which leads to the weak level of digitalization, automation, and informatization of China's manufacturing industry. Further, the resource utilization rate needs to be further improved.

(5) Obstacles in the system and mechanism still remain. The existing green assessment mechanism, institutional system, and incentive mechanism are not yet adapted to the requirements of the green transformation development of the manufacturing industry. For example, the standard specifications have not been strictly enforced, the verification mechanism has not been established, and the unfair enforcement of environmental protection has caused unfair competitions among enterprises.

\subsection{Strategic direction of engineering science and technology for promoting green manufacturing in China}

Based on the problems of the supply-side reform, transformation and upgrading, energy saving, and emission reduction of the Chinese manufacturing industry under the circumstances of the new normal, this paper proposes the strategic direction in engineering technology of China's green manufacturing.

\subsubsection{The period of the 13th Five-Year Plan}

We will vigorously promote energy efficiency, and significantly reduce pollution emissions, to accelerate the implementation of energy-saving development. We will strengthen the comprehensive utilization of resources, and continuously advance the circular development. We will reduce greenhouse gas emissions to actively promote a low-carbon transition. We will promote the implementation of "Green Manufacturing + Internet," to upgrade the green intelligent level of the manufacturing industry.

\subsubsection{The period of the 14th Five-Year Plan}

We will set near-zero emissions as the country's goal, to pursue the intensive, circular, and coupling symbiosis mode, and energetically develop green parks. We will set creating green factories, green products, green parks, green supply chain as the primary content, to strengthen the green supervision and build a green manufacturing system comprehensively. We will comprehensively construct intelligent green manufacturing factories, based on the maturity of physical information systems, cloud computing, Internet of Things, and other related technologies. We will popularize and improve the green and intelligent level of equipment based on the industrial internet, and vigorously develop green intelligent equipment. The representative major engineering, science, and technology projects to promote China's green manufacturing are shown in Table 1.

\section{Policy implications}

Currently, China is experiencing an important historical stage as it transforms from a large manufacturing country into a global manufacturing power [6]. With the green development concept, China must strive to advance the coordinated development between the manufacturing industry and ecological environment. Therefore, we now need to clarify the primary contradiction and highlight the key points, and strive to transform the extensive growth mode of the manufacturing industry with high consumption, high emissions, and low efficiency, while ensuring resource saving and an environment-friendly green development.

\subsection{Performing well in the top-level design, hierarchical leadership, and implementation of green development}

We should establish the strategic position of ecological civilization construction in the process of sustainable development of the manufacturing industry from the top strategic level. We should deepen the structural reform of ecological civilization, accelerate the compilation of the natural resources balance sheet, implement resources compensation and ecological compensation, and promote the balance between the development of the manufacturing industry and the resources, ecology, and environment.

We should focus on cultivating the strategic emerging industries that favor resource conservation, recycling, ecological restoration, and environmental protection. We should vigorously promote the structural transformation and upgrading of the traditional manufacturing industry, accelerate the elimination of backward production capacity, and strive to achieve the maximum in efficiency enhancement and pollution reducing by means of structural optimization, technological innovation, management upgrades, etc. We should construct eco-friendly industrial parks and green industrial chains, and implement the technical transformation and green management in all aspects of the product lifecycle.

We should accelerate the further study and formulate a comprehensive evaluation index system for green manufacturing 
Table 1. Representative major engineering science and technology projects to promote China's green manufacturing.

\begin{tabular}{|c|c|c|}
\hline Period & Industry classification & Major project content \\
\hline \multirow{17}{*}{$\begin{array}{l}\text { The period } \\
\text { of the 13th } \\
\text { Five-Year } \\
\text { Plan }\end{array}$} & \multirow[t]{10}{*}{$\begin{array}{l}\text { Typical process } \\
\text { industries }\end{array}$} & $\begin{array}{l}\text { Project of kiln exhaust gas purification and efficient and integrative comprehensive utilization for process } \\
\text { industries }\end{array}$ \\
\hline & & Short-flow project of green manufacturing for process industries \\
\hline & & Systematic project of comprehensive utilization of energy for process industries \\
\hline & & $\begin{array}{l}\text { Innovation project for chemical fertilizer industry connected with the circular development pattern of new } \\
\text { agriculture }\end{array}$ \\
\hline & & Demonstration project of circular economy for coastal base of steel, petrochemical, and construction materials \\
\hline & & Demonstration project for steel and construction material enterprises symbiotic with the city \\
\hline & & Digital manufacturing project \\
\hline & & Pilot demonstration project of intelligent manufacturing \\
\hline & & Demonstration base of remanufacturing project for petrochemical machinery in service \\
\hline & & $\begin{array}{l}\text { Demonstration base of networked monitoring and diagnosis of health energy efficiency for process industry } \\
\text { equipment }\end{array}$ \\
\hline & \multirow{7}{*}{$\begin{array}{l}\text { Equipment } \\
\text { manufacturing } \\
\text { industries }\end{array}$} & Demonstration project of basic manufacturing technology and equipment application \\
\hline & & Central project of specialized basic manufacturing technology \\
\hline & & Project of green digital workshop/factory \\
\hline & & Central project of recycling reutilization for basic manufacturing technology \\
\hline & & Project of industrial green assessment \\
\hline & & Brain Change Project of domestic numerical control system in the military industry \\
\hline & & Project of promoting the advanced technology application in the green remanufacturing field \\
\hline \multirow{6}{*}{$\begin{array}{l}\text { The period } \\
\text { of the 14th } \\
\text { Five-Year } \\
\text { Plan }\end{array}$} & \multirow{2}{*}{$\begin{array}{l}\text { Typical process } \\
\text { industries }\end{array}$} & Major project of efficient utilization of resources for process industries \\
\hline & & $\begin{array}{l}\text { Major project of synergistic optimization of material flow, energy flow, and information flow for process } \\
\text { industries }\end{array}$ \\
\hline & \multirow{4}{*}{$\begin{array}{l}\text { Equipment } \\
\text { manufacturing } \\
\text { industries }\end{array}$} & Project of green basic manufacturing technology and equipment \\
\hline & & Project of supervision of assessment and certification of green remanufacturing \\
\hline & & Demonstration project of green remanufacturing application \\
\hline & & Technological innovation project of intelligent, high-end equipment remanufacturing \\
\hline
\end{tabular}

from macro (country) to micro (regional and enterprise), and from industry wide to industry specific, and establish a hierarchical evaluation institution of the green manufacturing implementation effect, based on the research findings of the green manufacturing evaluation index system for typical process industries in Made in China 2025.

We should strengthen the construction of the leading team of green manufacturing. We suggest establishing the leading group at all levels: nation, region, industry, and enterprise, and hierarchically implementing the green manufacturing projects. Additionally, we could directly link the effect of green manufacturing with the performance evaluation of leading cadres at all levels, and implement a lifelong responsibility system, which could promote the level of green manufacturing in related areas and industries, through the "regional radiation effect" and the "industry benchmarking effect."

\subsection{Energetically promoting the construction of scientific and technological innovation system and service platform}

We should deepen the reform of the system of science and technology, strengthen the construction of the innovation system, and promote the combination of industry, university, research institute, and application, and the cross-field collaborative innovation. We should promote "open innovation," and comprehensively improve the enterprise's innovation consciousness and innovation ability. We should strengthen the combination of scientific research, and technology design and engineering, encourage the industrialization of scientific and technological achievements, and build a variety of forms of innovation alliance (including domestic and international exchange and cooperation platform, supporting integration and innovation).

We should strengthen the efforts to handle the key technologies. Aiming at the key technologies and bottleneck problems within the industries, the government should support and guide the scientific research institutes, industry associations, and enterprises to conduct joint research. Hence, the government should encourage intermediary organizations of associations to invite tenders for organizing efforts to handle key problems, followed by the government and enterprises to implement the purchase of services. The government might also encourage enterprises to establish research and development institutions, and perform 
research for engineering achievements [7]. For example, the basic research of mechanical fault diagnosis in the machinery and equipment of the process industry is weak, and a lack in the systems of intelligent chain protection, major accident prevention, and advanced optimized integrated control exist, which significantly affects the stable operation. Thus, such technical bottlenecks need to be solved urgently.

We should enhance the construction of the service platform for science and technology. First, we should strengthen the government's function of promoting the research of engineering, science, and technology innovations. We suggest the government and enterprises share risks to build and restructure a batch of engineering, science, and technology innovation platforms. Additionally, we should promote the deep integration of the green manufacturing technology innovation with information and finance, and conduct efforts to build the technical platform of intelligent management, the platform of green detection, and the investing and financing platform of green development, to create conditions for the independent innovation of core technology, the construction of intelligent green manufacturing plants, and the construction of low-carbon and circular economy industrial chains.

\subsection{Solving the institutional obstacles of the integration development of the manufacturing industry and ecological environment, and innovating the construction of system and mechanism}

We should improve the system and standards of laws and regulations in the key areas of green manufacturing. First, we suggest accelerating the legislative process of the Energy Law, promoting the enactment of the Low Carbon Development Promotion Law, the Emission Trading Law, and other special laws as soon as possible, and constantly improving the supporting measures of the Circular Economy Promotion Law, and other special laws and regulations (rules and mechanisms for the implementation). Next, we suggest formulating and improving the laws and regulations related to energy conservation assessment review, coping with climate change, soil environmental protection, water saving and pollutant emission permits, ecological compensation, compensation for ecological environmental damage, and other aspects, to provide effective legal guarantees for green development. Subsequently, we suggest constantly improving the process specifications, technical standards, and other aspects of technical regulations in the production process.

We should improve the market mechanism and supporting mechanism related to green manufacturing. To start, we should improve and optimize the financial support mechanism, and strengthen the special financial support measures by focusing on key projects of green manufacturing, to further utilize the support and guidance of fiscal policies to the engineering, science, and technology projects of green development related to intelligent green manufacturing factories (big data, cloud computing, information physical systems, internet of things, etc.), reconstruction of key energy conservation and environmental protection technologies, the "replacing old products with remanufactured products," and other aspects. Next, we should promote the environmental capitalization and resource capitalization, actively explore the market modes such as the resource-use right trading mode, and gradually establish market systems for trading energy saving, carbon emission rights, pollution discharge rights, water rights, etc. $[3,7]$. Moreover, we should improve the pricing mechanism of resources, pushing prices to fully reflect the social cost of the scarcity and use of mineral resources, water resources, and energy [7]. Finally, we should improve the related supporting mechanisms for green manufacturing, such as the mechanism of environmental protection law enforcement supervision and social supervision, evaluation mechanism, accountability mechanism, and coordination (linkage) mechanism.

\subsection{Participating in extensive international cooperation, and exploring the path to green manufacturing with Chinese characteristics}

By preserving the "seek common ground while reserving differences" principle, we should actively participate in and promote the multichannel, multilevel, and diversified international exchanges and cooperation in the sustainable development of the manufacturing industry, and attempt to gather support from the projects in the relevant international field. Additionally, we could introduce capitals, advanced technologies, and management experience, to seek the favorable international development space for China's green manufacturing [7].

On the one hand, we should learn from the United States, Germany, Japan, EU, and other developed countries and regions about their successful experiences in the implementation of green manufacturing (including ecological design, and standardization of product environmental footprint). On the other hand, we should gradually explore the path to green manufacturing with Chinese characteristics according to local conditions, based on the digestion and absorption of foreign experience and technologies. For instance, China has great development potential in raw material homogenization and the synergistic treatment of waste.

\section{Conclusions}

Green manufacturing is the only option to solve the difficult problem of the coordinated development between the manufacturing industry and ecological environment, for the harmonious coexistence between the industrial civilization and ecological civilization. Using process manufacturing and discrete manufacturing as the primary case study, we clarified the significance of promoting green manufacturing for China's manufacturing pow- 
er construction and ecological civilization construction, and proposed the strategic direction and countermeasures on the method to promote the full realization of efficient, clean, low-carbon, circular, and sustainable development of the manufacturing industry. The study shows that, to promote green manufacturing comprehensively, we should focus on the top-level design by strengthening the construction of the leadership team, innovation system of science and technology, service platform, and system and mechanism. We should also participate in extensive international cooperation, and meanwhile, explore the path to green manufacturing with Chinese characteristics.

\section{References}

[1] Jin Y, Arons J. Resource • energy • environment • society: Scientific and engineering principles for circular economy [M]. Beijing: Chemical Industry Press, 2009. Chinese.
[2] Chinese Academy of Engineering. Research on manufacturing power strategy $\bullet$ green manufacturing thematic volume $[\mathrm{M}]$. Beijing: Publishing House of Electronics Industry, 2016. Chinese.

[3] Du X W, Wen Z G, Wang N, et al. The backdrop and significance of ecological civilization construction [J]. Strategic Study of CAE, 2015, 17(8): 8-15. Chinese.

[4] Qian Y, He J K, Lu F. Fifteen lectures on ecological civilization [M]. Beijing: China Science Publishing \& Media Ltd., 2015. Chinese.

[5] Xu D L, Cui Y S, Li H, et al. On the future of Chinese cement industry [J]. On the future of Chinese Cement industry [J]. Cement and Concrete Research, 2015 (78): 2-13.

[6] Chinese Academy of Engineering. Research on manufacturing power strategy $\bullet$ comprehensive volume $[\mathrm{M}]$. Beijing: Publishing House of Electronics Industry, 2016. Chinese.

[7] Fu Z H, Song Z K, Chen X H, et al. Study on green development strategies for the industry in China [J]. Strategic Study of CAE, 2015, 17(8): 16-22. Chinese. 